\title{
44. Metabolism of Steroids
}

\section{The 7-Hydroxycholesterols as Metabolites}

\author{
By G. A. D. Haslewood, From Guy's Hospital Medical School, \\ Sherwood Park, Tunbridge Wells
}

(Received 17 March 1942)

The work of Wintersteiner \& Ritzmann [1940] and of Bergström \& Wintersteiner [1941] has demonstrated the presence of both $\alpha$-and $\beta$-7-hydroxycholesterol in various tissue extracts, and has indicated that these cholesterol oxidation products might arise, in part at least, during the isolation processes. It is clear also that there exist in the body the conditions (presence of cholesterol in fine suspension and of $\mathrm{O}_{2}$, and an alkaline reaction) which the American workers have shown to result in formation of 7-hydroxycholesterol in vitro [Bergström \& Wintersteiner, 1941]. The conclusion is that these substances may in fact be present in the blood and other tissues, and this conclusion has now been further tested, first by attempts at the isolation of 7-hydroxysterols from plant sources (yeast fat, acorn fat and wheat germ oil), and secondly by the saponification of cholesteryl stearate.

In the plant fats, no substances of the type under discussion were detected. Although, especially in a complex mixture such as yeast fat, 7-hydroxysterols may have escaped notice, it nevertheless seems reasonable to deduce that such sterols, if present at all, exist only in very small amounts, much smaller than are found in ox liver. The sitosterols of wheat germ and acorn fat are believed to contain the cholesterol nuclear structure (I) and are readily oxidized to what appear to be 7-hydroxy compounds by methods such as those used by Bergström \& Wintersteiner [1941] for cholesterol:

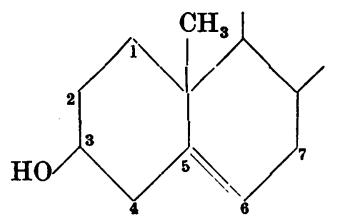

(I)

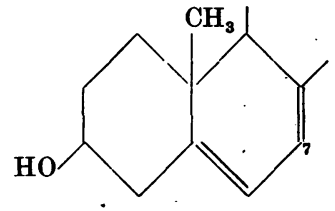

(II)

It is not known whether sterols of type (I) exist in yeast. Pure 'synthetic' cholesteryl stearate was saponified under the conditions used for the isolation of 7-hydroxycholesterol from ox liver. No oxidation products of this type could be detected. It therefore seems reasonable to conclude: (1) that if 7-hydroxycholesterol is formed during isolation procedures it is formed in very small amounts; (2) that most of the 7-hydroxycholesterol found in tissues is to be regarded as a cholesterol oxidation product existing there in vivo. There is as yet no experimental evidence whatever to show that the presence of 7-hydroxycholesterol is connected with the formation of 7-dehydrocholesterol (II), the precursor of vitamin $D_{3}$. Examination of a tunny liver oil of high vitamin $D$ assay showed the presence of only minute amounts of sterols of the 7-hydroxy type.

The methods used in this work were those previously described [Haslewood, 1939; 1941]. The isolation of digitonin-precipitable material, insoluble in light petroleum, and giving an intense blue colour with antimony trichloride [Barr et al. 1936], was taken as evidence of the presence of 7-hydroxysterols.

\section{Experimental}

General methods. The unsaponifiable portion of the fats was dissolved in alcohol and the precipitate of 'sterols' filtered off. The liquors, on evaporation, left Fraction A. This was fractionated between $90 \%$ methyl alcohol and light petroleum (l.p.), B.P. $40-60^{\circ}$, 
as previously described [Haslewood, 1941], the 1.p.-soluble containing Fraction B and the alcohol-soluble, Fraction C. Fraction $\mathrm{C}$ is cholesterol-free and readily yields 7-hydroxycholesterol in the case of ox-liver fat. Fraction B was further fractionated as described; when the starting material was ox-liver, this fraction also contained hydroxycholesterol.

Yeast fat. Starting material (supplied by Glaxo Laboratories) was the residue from the separation of ergosterol. When this (100 g.) was allowed to stand with benzene $(300 \mathrm{ml}$.), there separated a gelatinous solid which gave negative colour reactions. $30 \mathrm{ml}$. of the benzene filtrate were run through an $\mathrm{Al}_{2} \mathrm{O}_{3}$ column (Merck: diam. $1 \cdot 2 \mathrm{~cm}$., length $16 \mathrm{~cm}$.), and the column was washed with $400 \mathrm{ml}$. of benzene. Little or no digitoninprecipitable material was obtained after elution of the top half of the column. In other cases, the whole column was eluted with alcohol and acetone and the eluate, with digitonin in $80 \%$ alcohol and a little ether, gave $30-70 \mathrm{mg}$. of digitonide showing a blue colour of variable intensity with $\mathrm{SbCl}_{3}$ in chloroform. Decomposition of $0 \cdot 27 \mathrm{~g}$. of the accumulated digitonide with pyridine and ether yielded oily material, of which approximately $30 \mathrm{mg}$. were insoluble in 1.p. and gave a faint colour with $\mathrm{SbCl}_{3}$. No solid was obtained after benzoylation. Many experiments such as the above resulted only in the preparation of very intractable and apparently unstable gums, which may have contained some 7-hydroxysterols: this is, however, unlikely, for it is to be expected that these substances will be adsorbed from benzene solution on the top part of the column [Haslewood, 1939]. When the adsorption was carried out as above and the benzene was collected separately after the first drops leaving the column had become colourless, there was obtained on evaporation of this benzene a crystalline solid which was also part of the material which separated (see below) during the $90 \%$ methyl alcohol-l.p. fractionation. This substance, after recrystallization from dilute alcohol and then benzene, formed almost colourless needles, M.P. 110-111 ${ }^{\circ}$. (Found (by Dr H. Nisbet, Edinburgh): C, 69.7; $\mathrm{H}, 11 \cdot 3 \%$. Mol. wt. (Rast) $=390$. $\left(\mathrm{C}_{5} \mathrm{H}_{10} \mathrm{O}\right)_{n}$ requires $\mathrm{C}, 69 \cdot 8 ; \mathrm{H}, 11 \cdot 6 \%$.) This compound appeared to be an alcohol.

Variable amounts of solid material separated when the original fat was shaken with $90 \%$ methyl alcohol and 1.p. $2 \mathrm{~g}$. of this solid were shaken with benzene and the benzenesoluble portion, in benzene, was run through an $\mathrm{Al}_{2} \mathrm{O}_{3}$ column $(1.2 \times 10 \mathrm{~cm}$.) and washed with $250 \mathrm{ml}$. of the solvent. Evaporation of the benzene gave $0 \cdot 14 \mathrm{~g}$. of impure digitoninprecipitable 'sterol', M.P. $134-145^{\circ}$, giving a benzoate M.P. $161-165^{\circ}$, not affected by boiling dimethylaniline $(30 \mathrm{hr}$.). The substance and benzoate gave positive LiebermannBurchard.and Tortelli-Jaffé reactions, and intense bluish-purple colours with $\mathrm{SbCl}_{3}$. Fraction C (1-2 g. from $20 \mathrm{~g}$. of fat, after removal of about $1 \mathrm{~g}$. of the above solid and of benzene-insoluble material) yielded $0 \cdot 2-0 \cdot 3 \mathrm{~g}$. of digitonide which gave no colour with $\mathrm{SbCl}_{3}$ and no identifiable product after decomposition.

Acorn fat. Peeled, minced and dried acorns (from the English oak, Quercus Robur L.) were powdered and extracted in a Soxhlet apparatus with ether until the extract was colourless. Evaporation gave the fat as a dark oil. Yield, $150 \mathrm{~g}$. from $4 \cdot 75 \mathrm{~kg}$. of dried acorn powder.

This material in alcohol (400 ml.), with $\mathrm{KOH}$ (50 g.) in water $(50 \mathrm{ml}$.$) , was boiled under$ reflux for $6 \mathrm{hr}$. The mixture was cooled, diluted to $1900 \mathrm{ml}$., almost saturated with $\mathrm{NaCl}$ and extracted 4 times with ether. Evaporation of the washed ether gave the unsaponifiable matter as a yellowish solid $(2 \cdot 2 \mathrm{~g}$.). The 'sterols' crystallized from methyl alcohol as white plates (1 g.) of M.P. $117-130^{\circ}$, which, by the method of Windaus [1906; cf. Zaki \& Soliman, 1940], gave no stigmasterol tetrabromide. The recovered, debrominated and recrystallized acetate had M.P. 119-121 ${ }^{\circ}$, and the sitosterol obtained from this by saponification melted at $132-134^{\circ}$. The isterol' fraction also contained a small quantity of what appeared to be a hydrocarbon, M.P. $65^{\circ}$.

Fraction A (1.2 g.), dissolved in l.p., was run through an $\mathrm{Al}_{2} \mathrm{O}_{3}$ (Hopkin and Williams) column $(0.8 \times 15 \mathrm{~cm}$.) and the column was washed with $250 \mathrm{ml}$. of $1 . p$. $20 \mathrm{mg}$. of digitonide 
were isolated after elution of the top third of the column. In re-adsorptions, the whole of the adsorbed material was eluted. No fraction giving a perceptible colour with $\mathrm{SbCl}_{3}$ was isolated from any of the digitonides or eluates obtained. Acorn fat in the amounts examined contained no detectable 7-hydroxysterols.

The above sitosterol $(50 \mathrm{mg}$.) in acetone was added to $5 \mathrm{ml}$. of Castile soap solution (1 g./100 ml.) and the emulsion heated, with shaking, on the water bath until the smell of acetone had disappeared. After $12 \mathrm{hr}$. at approximately $80^{\circ}$, with occasional shaking, the mixture was acidified and extracted with ether. Evaporation of the ether, after washing with $\mathrm{NaOH}$ and water, left a gum which with l.p. yielded $5 \mathrm{mg}$. of crystals (probably impure 7-hydroxysitosterol) of M.P. 145-149 ${ }^{\circ}$, giving an intense blue colour with $\mathrm{SbCl}_{3}$. A similar fraction was obtained in the same way from stigmasterol.

Wheat germ oil. Fraction A was supplied by Glaxo Laboratories. Fraction C from $10 \mathrm{~g}$. (corresponding to about $20 \mathrm{~g}$. of 'sterols') of Fraction A weighed $0 \cdot 25 \mathrm{~g}$. and yielded $40 \mathrm{mg}$. of a digitonide mixed with a yellow pigment that gave an intense $\mathrm{SbCl}_{3}$ reaction. Decomposition of the digitonide gave a residue completely soluble in l.p. and yielding on re-precipitation with digitonin a small amount of a product not chromogenic with $\mathrm{SbCl}_{3}$.

Fraction $\mathrm{B}$, or the original oil (5 g.), in l.p., was adsorbed on an $\mathrm{Al}_{2} \mathrm{O}_{3}$ (Hopkin and Williams) column $(0.8 \times 20 \mathrm{~cm}$.), which was then washed with $500 \mathrm{ml}$. of l.p. The digitonide obtained after elution of the top third of the column strongly adsorbed the above pigment and on decomposition gave material entirely soluble in l.p. In chloroform, this mixture gave an intense purplish colour with $\mathrm{SbCl}_{3}$; it appeared to be similar to the corresponding fraction from yeast fat. Washing of the whole column with ether, a procedure which had given 7-hydroxycholesterol from ox liver fat [Haslewood, 1941], yielded a fraction from which were prepared $1 \cdot 2 \mathrm{~g}$. of digitonide, by addition of successive amounts $(0.5,0 \cdot 3,0.2,0.2$, and $0.2 \mathrm{~g}$.) of digitonin, the precipitates being collected separately and tested with $\mathrm{SbCl}_{3}$. The first $0.8 \mathrm{~g}$. of digitonin gave $1.0 \mathrm{~g}$. of digitonide not chromogenic with $\mathrm{SbCl}_{3}$, and leaving, after decomposition, a sterol of M.P. 134-137 . The remaining $0.2 \mathrm{~g}$. of digitonide was chromogenic with $\mathrm{SbCl}_{3}$; the sterol from it was soluble in l.p. and similar to the fraction from the top part of the $\mathrm{Al}_{2} \mathrm{O}_{3}$ column, the $\mathrm{SbCl}_{3}$ test showing a green to blue-green colour.

Saponification of cholesteryl stearate. Cholesteryl stearate (10 g., M.P. 84-85 ${ }^{\circ}$, prepared from cholesterol and a pyridine solution of redistilled acid chloride, from stearic acid of M.P. 70-71 ${ }^{\circ}$ ) was boiled for $5 \mathrm{hr}$. under reflux with $\mathrm{KOH}(10 \mathrm{~g}$.) and $50 \%$ alcohol $(150 \mathrm{ml}$.$) ,$ and allowed to stand for $20 \mathrm{hr}$. Examination of the unsaponifiable material (prepared as usual after ether extraction) by the methods mentioned gave only cholesterol, no 7-hydroxycholesterol being detected.

\section{SUMmary}

In a careful examination of yeast fat, acorn fat, wheat germ oil and the neutral fraction from saponified cholesteryl stearate, no 7 -hydroxysterols could with certainty be detected. It is concluded that these sterols are formed, if at all, only in very small amounts during isolation procedures. The 7-hydroxycholesterols are therefore probably to be regarded as 'genuine' intermediates in cholesterol metabolism.

The author expresses his sincere thanks to Dr E. L. Smith, of Glaxo Laboratories, for generous gifts of yeast fat residues and of wheat germ fractions.

\section{REFERENCES}

Barr, T., Heilbron, I. M., Parry, E. G. \& Spring, F. S. [1936]. J. chem. Soc. p. 1437.

Bergström, S. \& Wintersteiner, O. [1941]. J. biol. Chem. 141, 597.

Haslewood, G. A. D. [1939]. Biochem. J. 33, 709. - [1941]. Biochem. J. 35, 708.

Windaus, A. [1906]. Ber. dtsch. chem. Ges. 39, 437.

Wintersteiner, O. \& Ritzmann, J. R. [1940]. J. biol. Chem. 136, 697.

Zaki, A. \& Soliman, G. [1940]. J. chem. Soc. p. 1545. 